\title{
Comparison of different methods of goat sperm selection and capacitation for optimization of assisted reproductive technologies
}

\author{
Carolina Cerqueira Sarmento Olivares ${ }^{\mathrm{a}}$, Jeferson Ferreira da Fonseca ${ }^{\mathrm{b}}$, \\ Luiz Sérgio de Almeida Camargo ${ }^{c}$, Joanna Maria Gonçalves de Souza-Fabjan ${ }^{a, *}$, \\ André Luís Rios Rodrigues ${ }^{\mathrm{a}}$, Felipe Zandonadi Brandão ${ }^{\mathrm{a}}$ \\ a Faculty of Veterinary Medicine, Fluminense Federal University, Av. Vital Brasil Filho, 64, CEP 24230-340 Niterói, RJ, Brazil \\ b Embrapa Goats and Sheep, Estrada Sobral/Groaíras, km 04, CP 145, CEP 62010-970 Sobral, CE, Brazil \\ c Embrapa Dairy Cattle Research Center, Rua Eugênio do Nascimento, 610, CEP 36038-330, Juiz de Fora, MG, Brazil
}

\section{A R T I C L E I N F O}

\section{Article history:}

Received 26 June 2014

Received in revised form 9 April 2015

Accepted 10 April 2015

Available online 27 April 2015

\section{Keywords:}

Capacitation

Caprine

Sodium nitroprusside

Sperm preparation

Sperm selection

\begin{abstract}
A B S T R A C T
This study evaluated different methods of frozen-thawed sperm selection and capacitation in goats for further use in reproductive biotechnologies. In Experiment 1, semen was processed by the following techniques: mini-Percoll, swim-up, or washing by centrifugation. In Experiment 2, mini-Percoll selected-sperm was subjected to capacitation induction by incubation with: $50 \mu \mathrm{g} / \mathrm{mL}$ heparin, $10 \mu \mathrm{M}, 50 \mu \mathrm{M}$, or $100 \mu \mathrm{M}$ of sodium nitroprusside (SNP). Motility, vigor, acrosome, and plasma membrane (PM) integrity were evaluated after thawing and after each treatment of sperm selection or capacitation. In Experiment 1, washing by centrifugation presented greater $(43 \% ; P<0.05)$ spermatozoa recovery rate than the other treatments. The swim-up technique showed the lowest $(P<0.05)$ progressive motility $(41 \%)$. Spermatozoa presenting both intact PM $(P=0.0002)$ and acrosome $(P=0.0004)$ showed an interaction effect between the buck and swim-up technique. In Experiment 2 , the addition of $100 \mu \mathrm{M}$ SNP resulted in greater $(P<0.05)$ motility and vigor $(38 \% ; 4.7)$, respectively, than did heparin $(28 \% ; 4.3)$. An enhancement $(P<0.05)$ in vigor was obtained after all treatments in comparison with the evaluation after thawing (3.3). In conclusion, mini-Percoll was better than swim-up for preparing frozen-thawed goat sperm, whereas washing by centrifugation technique presented similar rates to mini-Percoll and could also be used. The use of $100 \mu \mathrm{M}$ SNP resulted in better motility and vigor than heparin treatment.
\end{abstract}

(C) 2015 Elsevier B.V. All rights reserved.

\section{Introduction}

The in vitro embryo production (IVP) has the advantage of selecting and using both male and female gametes, allowing the birth of several kids from a single high

\footnotetext{
* Corresponding author. Tel.: +55 212629 2595; fax: +55 2126292433

E-mail address: joannavet@gmail.com (J.M.G. de Souza-Fabjan).
}

genetic merit female. Many studies have been carried out in an attempt to determine the most suitable conditions for in vitro maturation, fertilization and development in order to maximize goat embryo production rate and quality (Souza-Fabjan et al., 2014). Among the different factors that may affect IVP results, probably the main ones are oocyte (Souza-Fabjan et al., 2014) and spermatozoa quality (Hansen, 2006). However, studies on goat spermatozoa preparation have received little 
attention in IVP systems (Palomo et al., 1999; Rho et al., 2001).

The introduction of in vitro fertilization (IVF) during the 1980s led to the development of a wide range of different sperm separation methods. Initially, the sperm preparation started with simple washing of spermatozoa and then evolved to separation techniques based on principles like migration, or density gradient centrifugation. The ideal sperm separation technique should (i) be quick, easy and cost-effective, (ii) isolate as much motile spermatozoa as possible, (iii) not cause sperm damage or nonphysiological alterations of the separated sperm cells, (iv) eliminate dead spermatozoa and other cells, including leukocytes and bacteria, (v) eliminate toxic or bioactive substances like decapacitation factors or reactive oxygen species (ROS), and (vi) allow processing larger volumes of ejaculates (Henkel and Schill, 2003).

In 1990, a method of sperm preparation consisting of a reduced volume of a discontinuous Percoll gradient (miniPercoll) was proposed (Ord et al., 1990). The two-layer Percoll gradient showed a higher sperm recovery than the mini-Percoll method, but the latter resulted in a higher percentage of motility and a higher sperm survival rate at $24 \mathrm{~h}$ (Kunathikom et al., 1998). However, the number of studies on the effect of swim-up and Percoll methods on goat spermatozoa is very limited in comparison with human or bovine, and the present authors are not aware of any published study comparing the goat spermatozoa obtained by swim-up or mini-Percoll separation on goats.

Spermatozoa must undergo capacitation and acrosome reaction to be able to fertilize, causing the release of proteolytic enzymes that may assist sperm penetration into the oocyte. Any agent that causes $\mathrm{Ca}^{2+}$ entry into the sperm acrosome and an increase of intracellular pH enables capacitation and later fertilization to be accomplished (Amoah and Gelaye, 1997). However, efficient systems for induction of capacitation and acrosome reaction of goat spermatozoa were still not established. It was already reported the use of heparin (Zhou et al., 2004), caffeine (Pereira et al., 2000; Lv et al., 2009), calcium ionophore (Pereira et al., 2000; Lv et al., 2009) and estrus sheep serum (Souza-Fabjan et al., 2014) as capacitating agents for goat semen. The mechanism for sperm capacitation of sodium nitroprusside (SNP) is related to the release of nitric oxide that induces the capacitation by means of intracellular mechanisms that seem to be involved with the activation of protein kinases (Rodriguez et al., 2005). Even though the efficiency of SNP was already evaluated in many species, such as bovine (Rodriguez et al., 2005) and bubaline (Boccia et al., 2007), it was never tested in caprine spermatozoa.

The aim of the present study was to enhance spermatozoa quality for assisted reproduction by comparing the effectiveness of: (i) mini-Percoll, swim-up, and washing by centrifugation procedures on the collection of high-quality frozen-thawed goat spermatozoa and (ii) heparin or SNP at different concentrations as capacitating agents.

\section{Materials and methods}

All the experiments were carried out at Fluminense Federal University (UFF), Niterói (Brazil, latitude $22^{\circ} 53^{\prime} \mathrm{S}$, longitude $43^{\circ} 06^{\prime} \mathrm{W}$ ). The procedures were approved by the local ethic committee (protocol approval:
159/11). Two experiments were performed to examine the impact of different spermatozoa preparation techniques using goat semen.

\subsection{Reagents}

All chemicals were from Sigma Chemical (St. Louis, MO, USA). Exceptions were Percoll gradients (90 and 45\%) and buffered saline solution (DPBS; Dulbecco's Phosphate Buffered Saline) obtained from Nutricell (Campinas, Brazil) and Giemsa staining acquired from Reagen Quimibrás (Rio de Janeiro, Brazil).

\subsection{Animals and spermatozoa samples}

Commercial semen straws from the same batch (ejaculate) from Saanen bucks, aging 2-5 years old, sexually matured and of proved fertility were used. All straws were maintained frozen in liquid nitrogen until their use. The data presented were obtained from nine bucks (Experiment 1 ) or seven bucks (Experiment 2), using one straw from each buck per treatment. In both experiments, all treatments were repeated three times (triplicates). Each replicate of all treatments was performed in the same day and by the same operator.

\subsection{Experiment 1}

Semen straws of $0.25 \mathrm{~mL}$ were thawed at $38^{\circ} \mathrm{C}$ for $30 \mathrm{~s}$ and homogenized in warmed microtubes. After thawing, each dose/straw was subjected to a different method of spermatozoa selection: mini-Percoll gradient, swim-up or spermatozoa washing by centrifugation. For all treatments, after thawing, spermatozoa were subjected to concentration, progressive motility (0-100\%), and vigor analysis (0-5). After the different spermatozoa selection techniques, besides the same evaluations, spermatozoa recovery rate and acrosome and plasma membrane integrity were also observed.

\subsubsection{Mini-Percoll density gradient}

In view of the batch-dependence of the quality of Percoll (Avery and Greve, 1995) it is necessary to note, that during the experiments the density gradients were made from the same batch of Percoll. The gradient was formed by pipetting $400 \mu \mathrm{L}$ of $90 \%$ Percoll solution into a $2 \mathrm{~mL}$ microtube and then overlaying it with $400 \mu \mathrm{L}$ of $45 \%$ Percoll solution (Machado et al., 2009). After the preparation, the microtube was warmed to $37^{\circ} \mathrm{C}$. One straw was placed onto the top of the $45 \%$ layer and then centrifuged at $14,000 \times g$ at room temperature for $5 \mathrm{~min}$. After removal of supernatant, the resulting pellet was washed with $400 \mu \mathrm{L}$ HEPES-TALP, supplemented with $3 \mathrm{mg} / \mathrm{mL}$ BSA V, $2.2 \mathrm{mg} / \mathrm{mL}$ sodium pyruvate, $50,000 \mathrm{IU} / \mathrm{mL}$ penicillin and $50 \mathrm{mg} / \mathrm{mL}$ streptomycin by centrifugation at $700 \times \mathrm{g}$ for $3 \mathrm{~min}$. Finally, the pellet was resuspended in $200 \mu \mathrm{L}$ of HEPES-TALP.

\subsubsection{Swim-up}

Swim-up procedure was previously described by Parrish and Foote (1987) but modified TALP was used in the present study. Frozen-thawed sperm from one straw was carefully placed in the bottom of a $15 \mathrm{~mL}$ tube containing $1 \mathrm{~mL}$ HEPES-TALP supplemented with $3 \mathrm{mg} / \mathrm{mL}$ BSA V, $2.2 \mathrm{mg} / \mathrm{mL}$ sodium pyruvate, $50,000 \mathrm{IU} / \mathrm{mL}$ penicillin and $50 \mathrm{mg} / \mathrm{mL}$ streptomycin. Spermatozoa were allowed to swim-up for $1 \mathrm{~h}$, at $37^{\circ} \mathrm{C}$ in a humidified $5.0 \% \mathrm{CO}_{2}$ (in air) atmosphere. After incubation, the supernatant containing the spermatozoa was harvested and transferred to another tube containing $1 \mathrm{~mL}$ of HEPES-TALP and centrifuged at $300 \times \mathrm{g}$ for $8 \mathrm{~min}$. Finally, the pellet was resuspended in $200 \mu \mathrm{L}$ of HEPES-TALP.

\subsubsection{Spermatozoa washing by centrifugation}

After thawing, semen from one straw was placed in a conic tube containing $10 \mathrm{~mL}$ of DPBS and washed once by centrifugation at $300 \times \mathrm{g}$ for $20 \mathrm{~min}$. After discarding the supernatant the spermatozoa pellet was resuspended in $500 \mu \mathrm{L}$ of DPBS.

\subsection{Experiment 2}

After thawing, two semen straws (due to the amount needed) were placed into a $2 \mathrm{~mL}$ microtube previously warmed and subjected to spermatozoa selection by mini-Percoll gradient method (as described in Experiment 1). After the mini-Percoll procedure, the selected spermatozoa was washed in SPERM-TALP (Parrish et al., 1988) supplemented with $6 \mathrm{mg} / \mathrm{mL}$ BSA V, $2.2 \mathrm{mg} / \mathrm{mL}$ sodium pyruvate, $50,000 \mathrm{IU} / \mathrm{mL}$ penicillin and 
Table 1

Spermatozoa evaluation post-thawing and after different methods of spermatozoa selection in goat frozen-thawed semen of Saanen breed ( $m e a n \pm S E M)$.

\begin{tabular}{|c|c|c|c|c|c|c|c|c|}
\hline \multirow[t]{2}{*}{ Selection method } & \multirow[t]{2}{*}{$n^{*}$} & \multicolumn{3}{|l|}{ After thawing } & \multicolumn{3}{|l|}{ After selection } & \multirow[t]{2}{*}{ Sperm recovery rate (\%) } \\
\hline & & $\begin{array}{l}\text { Concentration } \\
\left(\times 10^{6} / \mathrm{mL}\right)\end{array}$ & Motility (\%) & Vigor (1-5) & $\begin{array}{l}\text { Concentration } \\
\left(\times 10^{6} / \mathrm{mL}\right)\end{array}$ & Motility (\%) & Vigor (1-5) & \\
\hline Swim-up & 27 & $126.1 \pm 11.2^{\mathrm{b}}$ & $55.1 \pm 1.9$ & $3.5 \pm 0.1$ & $3.5 \pm 0.7^{c}$ & $41.1 \pm 5.0^{\mathrm{b}}$ & $4.0 \pm 0.2$ & $2.3 \pm 0.3^{c}$ \\
\hline Mini-Percoll & 27 & $194.9 \pm 26.4^{\mathrm{a}}$ & $55.5 \pm 2.5$ & $3.4 \pm 0.1$ & $41.9 \pm 4.6^{\mathrm{b}}$ & $55.5 \pm 2.6^{\mathrm{a}}$ & $4.0 \pm 0.1$ & $28.1 \pm 3.3^{b}$ \\
\hline Washing $^{* *}$ & 27 & $122.0 \pm 12.3^{b}$ & $51.8 \pm 2.9$ & $3.3 \pm 0.1$ & $55.4 \pm 7.0^{\mathrm{a}}$ & $50.7 \pm 3.2^{\mathrm{a}}$ & $4.2 \pm 0.1$ & $43.3 \pm 3.8^{a}$ \\
\hline
\end{tabular}

Within a column, values without a common superscript (a,b,c) differ significantly by Student-Newman-Keuls $(P<0.05)$.

* Data obtained from nine bucks in triplicates.

** Washing by centrifugation technique.

$50 \mathrm{mg} / \mathrm{mL}$ streptomycin by centrifugation for $3 \mathrm{~min}$ at $700 \times \mathrm{g}$. Moreover, to verify the post-thawing parameters with no influence of the sperm selection, one semen straw was subjected to three consecutive centrifugations ( $300 \times \mathrm{g}$ for $8 \mathrm{~min}$ ) in $2 \mathrm{~mL}$ of HEPES-TALP medium containing $125 \mathrm{mM} \mathrm{NaCl}, 3.1 \mathrm{mM} \mathrm{KCl}, 0.4 \mathrm{mM} \mathrm{NaH}_{2} \mathrm{PO}_{4}, 21.6 \mathrm{mM} \mathrm{NaC}_{3} \mathrm{H}_{5} \mathrm{O}_{3}, 2 \mathrm{mM}$ $\mathrm{NaHCO}_{3}, 2 \mathrm{mM} \mathrm{CaCl}, 1.06 \mathrm{mM} \mathrm{MgCl}, 10 \mathrm{mM}$ HEPES and supplemented with $1 \mathrm{mg} / \mathrm{mL}$ BSA V, $2.2 \mathrm{mg} / \mathrm{mL}$ sodium pyruvate, $50,000 \mathrm{IU} / \mathrm{mL}$ penicillin and $50 \mathrm{mg} / \mathrm{mL}$ streptomycin.

The post-thawing and Mini Percoll-selected sperm samples were subjected to capacitation induction by incubation for $45 \mathrm{~min}$ at $38.5^{\circ} \mathrm{C}$ (Zhou et al., 2004) in a humidified $5.0 \% \mathrm{CO}_{2}$ (in air) atmosphere with: $50 \mu \mathrm{g} / \mathrm{mL}$ heparin (Zhou et al., 2004); $10 \mu \mathrm{M}$ (Boccia et al., 2007), $50 \mu \mathrm{M}$, or $100 \mu \mathrm{M}$ of SNP(Rodriguez et al., 2005); or in the absence of capacitating agents (control group). Each treatment group contained $1 \times 10^{7}$ spermatozoa within $1 \mathrm{~mL}$ SPERM-TALP. After the incubation period, $100 \mu \mathrm{L}$ of lysophosphatidylcholine, a fusogenic lipid that induces acrosome reaction in capacitating spermatozoa (Parrish et al., 1988), was added to each group (including post-thawing and control groups), and spermatozoa remained incubated for 15 more min (Parrish et al., 1988), to evaluate the capacitating spermatozoa by its acrosome reaction. After the treatments, progressive motility (0-100\%), vigor analysis (0-5), acrosome and plasma membrane integrity were observed.

\subsection{Spermatozoa evaluation}

Spermatozoa were evaluated regarding their progressive motility, vigor and acrosome and plasma membrane integrity after the different methods of selection (Experiment 1) and capacitation (Experiment 2) as well as for control group. Motility and vigor were subjectively analyzed in three different fields by the same technician under light microscope at $400 \times$. Vigor (frequency of flagellar beating) was classified in a scale of $0-5$ and progressive motility from 0 to $100 \%$ (CBRA, 1998). Spermatozoa recovery rate was obtained after each spermatozoa selection method and analyzed by the use of a Neubauer counting chamber after spermatozoa dilution $(1: 200)$. The rate was calculated by the formula: [final concentration $\times$ final volume $\times[\text { initial concentration } \times \text { initial volume }]^{-1} \times 100$. Acrosome and plasma membrane (PM) integrity were determined by the use of $0.2 \%$ tripan blue and $10 \%$ giemsa staining procedure (Didion et al., 1989). Trypan blue penetrates in spermatozoa with disrupted (nonintact) PM, which stain in blue, whereas intact PM spermatozoa appeared unstained. Giemsa accumulates in spermatozoa with an intact acrosome, staining the acrosome region in purple or pink, while damaged (nonintact) acrosome appeared unstained.

\subsection{Statistical analysis}

All quantitative variables were subjected to normality (Shapiro-Wilk test) and homoscedasticity tests and one-way analysis of variance (ANOVA) was performed with Student-Newman-Keuls for means comparisons. The same tests were applied to identify the treatment-buck interaction. A value of $P<0.05$ was considered to be statistically significant. Statistical analyses were performed using statistical analysis system for Windows SAS ${ }^{\mathrm{TM}}$ software.

\section{Results}

\subsection{Experiment 1}

The method of washing by centrifugation presented greater $(P<0.05)$ spermatozoa concentration after subjected to sperm selection in comparison with miniPercoll or swim-up techniques, reflecting a greater spermatozoa recovery rate (Table 1 ). The swim-up technique showed the lowest $(P<0.05)$ progressive motility evaluated after the different selection methods, whereas mini-Percoll and washing by centrifugation were similar. Vigor was not different $(P>0.05)$ after all three treatments (Table 1).

When analyzing intact PM and intact acrosome sperm population, there was no difference $(P>0.05)$ among all three selection methods (Table 2). The proportion of intact PM but with non-intact acrosome was higher $(P<0.05)$ for swim-up method than the other treatments (Table 2). When investigating the non-intact PM, the acrosome intact sperm population subjected to mini-Percoll treatment presented the highest $(P<0.05)$ percentage in comparison with swim-up (Table 2).

The number of spermatozoa presenting both intact PM $(P=0.0002)$ and acrosome $(P=0.0004)$ showed an interaction effect between the buck and swim-up technique, whereas the other methods were not affected by the use of frozen-thawed sperm from different males.

\subsection{Experiment 2}

Post-thawing progressive motility was higher $(P<0.05)$ than in the control group or after all treatments for capacitation (Table 3). The addition of $100 \mu \mathrm{M}$ SNP resulted in greater $(P<0.05)$ motility than the group receiving heparin. An enhancement $(P<0.05)$ in vigor was obtained after the use of any treatment tested in comparison with the evaluation immediately after thawing. The presence of SNP in any concentration promoted greater vigor than in the control group. Moreover, the group exposed to the highest concentration tested showed greater $(P<0.05)$ vigor than heparin treatment. Post-thawing analysis showed greater rate of intact PM and intact acrosome spermatozoa population than after any capacitation treatment or control group. The percentage of cells with intact PM and non-intact acrosome were similar $(P>0.05)$ among all the treatments (Table 3$)$.

\section{Discussion}

There have been many reports comparing different spermatozoa isolation techniques in humans and bovine. In goats, spermatozoa preparation for IVF is generally based on the selection of motile spermatozoa by swim-up or Percoll (Reviewed by Souza-Fabjan et al., 2014), with 
Table 2

Plasma membrane (PM) and acrosome integrity evaluation obtained after different methods of spermatozoa selection in goat frozen-thawed semen of Saanen breed (mean \pm SEM).

\begin{tabular}{|c|c|c|c|c|c|}
\hline \multirow[t]{2}{*}{ Selection method } & \multirow[t]{2}{*}{$n^{*}$} & \multicolumn{2}{|c|}{ Intact PM sperm (\%) } & \multicolumn{2}{|c|}{ Non-intact PM sperm (\%) } \\
\hline & & Intact acrosoma & Non-intact acrosoma & Intact acrosoma & Non-intact acrosoma \\
\hline Swim-up & 27 & $47.0 \pm 3.7$ & $4.0 \pm 0.8^{\mathrm{a}}$ & $13.5 \pm 1.2^{\mathrm{b}}$ & $35.3 \pm 3.7^{b}$ \\
\hline Mini-Percoll & 27 & $45.7 \pm 2.4$ & $1.8 \pm 0.3^{\mathrm{b}}$ & $18.5 \pm 1.6^{\mathrm{a}}$ & $34.1 \pm 2.0^{\mathrm{b}}$ \\
\hline Washing $^{* *}$ & 27 & $44.7 \pm 3.3$ & $2.5 \pm 0.4^{\mathrm{b}}$ & $15.5 \pm 1.6^{\mathrm{a}, \mathrm{b}}$ & $37.6 \pm 3.0^{\mathrm{a}, \mathrm{b}}$ \\
\hline
\end{tabular}

Within a column, values without a common superscript (a,b,c) differ significantly by Student-Newman-Keuls $(P<0.05)$.

${ }^{*}$ Data obtained from nine bucks in triplicates.

${ }^{* * *}$ Washing by centrifugation technique.

few studies reporting washing by centrifugation method (Masudul Hoque et al., 2012). A limited number of studies have dealt with the simultaneously comparison of these sperm treatment methods in sheep (Martí et al., 2006) or in goats only using fresh sperm (Palomo et al., 1999). For the first time, we have demonstrated that goat spermatozoa may be efficiently selected by mini-Percoll technique.

The greatest spermatozoa recovery rate in the present study was achieved by washing technique. It is noteworthy that sperm washing removes the seminal plasma and extender but does not separate the sperm from other cells. Thus, the technique is not based on their quality or functional capacity (Mehta and Sigman, 2014) and both motile and non-motile sperm are retained. Sperm preparation for IVF can be done by washing with no deleterious effect on cleavage or blastocyst rates (Avery and Greve, 1995). Later studies using this technique obtained cleavage rates of $39 \%$ (Masudul Hoque et al., 2012) and 51\% after IVF, higher than the swim-up technique (43\%) (Palomo et al., 1999). Dode et al. (2002) highlighted that washing is a very easy, fast and economic method for bovine, when compared with other expensive and time consuming methods. The authors concluded that a sufficient number of sperm capable of fertilizing are available at washing and that sperm concentration used for IVF can overcome the possible differences in the sperm quality.

Mini-Percoll density gradient was $\sim 12$ times more efficient than swim-up in recovering spermatozoa from goat frozen-thawed sperm. More importantly, mini-Percoll treatment resulted in higher number of viable spermatozoa than swim-up procedure. This is in accordance with a previous study which reported a recovery of 33.9\% after Percoll and $7.7 \%$ after swim-up also in goat frozen-thawed sperm (Rho et al., 2001). Since 1999, Percoll has not been allowed for the separation of human spermatozoa for therapeutic use because of the detrimental action of the polyvinyl pyrrolidone that it contains (WHO, 1999). Therefore, an effort of using mini-Percoll, which contains one fourth of the amount of Percoll should be done in veterinary sciences, even though the spermatozoa recovery rate could be slightly lower.

The swim-up procedure remains the oldest sperm preparation method currently in use, even though the decrease in spermatozoa motility has been reported. Its advantage is the yield of $>90 \%$ of morphologically normal motile sperm, without other cells or debris. However, the absolute yield of sperm is low because motile spermatozoa in the lower levels of the pellet never reach the interface with the overlying culture medium (reviewed by Mehta and Sigman, 2014). Additionally, functional spermatozoa can come into close cell-to-cell contact with defective sperm or leukocytes by centrifugation, thus causing massive oxidative damages of the sperm plasma membrane by ROS and consequently of sperm functions (Henkel and Schill, 2003). The production of ROS by spermatozoa is a normal physiological process required for the occurrence of capacitation and the acrosome reaction. However, high levels of ROS present in seminal plasma have been associated with poor morphology, motility and low sperm count (Lopes et al., 1998). This stress to the spermatozoa is probably related to the relatively lengthy time period required for sperm recovery when employing swim-up technique. The feasibility of reducing the procedure time could be further evaluated in order to improve sperm quality. Moreover, it

Table 3

Spermatozoa evaluation post-thawing and after different treatments of spermatozoa capacitation in goat frozen-thawed semen selected by mini-Percoll on progressive motility, vigor, acrosomal and plasma membrane (PM) integrity (mean \pm SEM).

\begin{tabular}{|c|c|c|c|c|c|c|c|}
\hline \multirow[t]{2}{*}{ Treatment } & \multirow[t]{2}{*}{$n^{*}$} & \multirow[t]{2}{*}{ Motility (\%) } & \multirow[t]{2}{*}{ Vigor $(1-5)$} & \multicolumn{2}{|c|}{ Intact PM sperm (\%) } & \multicolumn{2}{|c|}{ Non-intact PM sperm (\%) } \\
\hline & & & & Intact acrosome & Non-intact acrosome & Intact acrosome & Non-intact acrosome \\
\hline Post-thawing & 21 & $57.6 \pm 2.4^{\mathrm{a}}$ & $3.3 \pm 0.1^{\mathrm{d}}$ & $32.0 \pm 2.9^{\mathrm{a}}$ & $2.1 \pm 0.3$ & $15.5 \pm 1.8$ & $45.8 \pm 3.8$ \\
\hline Control $^{* *}$ & 21 & $34.0 \pm 3.9^{b, c}$ & $4.2 \pm 0.1^{c}$ & $19.1 \pm 2.3^{b}$ & $2.5 \pm 0.1$ & $19.8 \pm 0.2$ & $53.8 \pm 4.1$ \\
\hline Heparin $^{* * *}$ & 21 & $28.1 \pm 3.6^{c}$ & $4.3 \pm 0.2^{b, c}$ & $16.8 \pm 1.9^{b}$ & $2.5 \pm 0.4$ & $24.6 \pm 2.5$ & $51.4 \pm 4.3$ \\
\hline $10 \mu \mathrm{M} \mathrm{SNP}{ }^{* * * *}$ & 21 & $34.3 \pm 3 ; 1^{b, c}$ & $4.5 \pm 0.1^{\mathrm{a}, \mathrm{b}}$ & $20.7 \pm 2.5^{b}$ & $2.9 \pm 0.4$ & $20.1 \pm 2.3$ & $51.6 \pm 4.1$ \\
\hline $50 \mu \mathrm{M}$ SNP & 21 & $36.2 \pm 3.1^{\mathrm{b}, \mathrm{c}}$ & $4.5 \pm 0.1^{\mathrm{a}, \mathrm{b}}$ & $19.0 \pm 2.3^{b}$ & $3.6 \pm 0.6$ & $21.3 \pm 2.6$ & $52.5 \pm 4.2$ \\
\hline $100 \mu \mathrm{M}$ SNP & 21 & $38.3 \pm 3.5^{\mathrm{b}}$ & $4.7 \pm 0.1^{\mathrm{a}}$ & $20.8 \pm 2.3^{b}$ & $2.9 \pm 0.4$ & $20.4 \pm 2.1$ & $51.3 \pm 3.9$ \\
\hline
\end{tabular}

Within a column, values without a common superscript (a,b,c) differ significantly by Student-Newman-Keuls $(P<0.05)$.

* Data obtained from seven bucks in triplicates.

** Control group: absence of capacitating agent.

*** $50 \mu \mathrm{g} / \mathrm{mL}$ heparin.

SNP: sodium nitroprusside. 
was demonstrated that spermatozoa exposed to ROS for $1 \mathrm{~h}$ have an increased DNA fragmentation rate (Lopes et al., 1998).

Palomo et al. (1999) compared swim-up, Percoll gradient, and centrifugation in simple media using freshly ejaculated prepubertal goat semen. Interestingly, they found that the swim-up procedure resulted in spermatozoa with significantly better motility, viability and acrosome integrity than did Percoll density gradient. Their study differed from ours since we used frozen-thawed sperm. In the present study, swim-up technique promoted both lower spermatozoa recovery rate and progressive motility than the other methods, which is in accordance with an earlier report in goat frozen-thawed sperm (Rho et al., 2001). These data may suggest that Percoll could be indicated when working with frozen sperm whereas swim-up when using fresh sperm.

It is well known that PM and acrosome integrity, essential to sperm vitality and longevity, are both affected by cryopreservation (Amann and Pickett, 1987). The greater percentage of intact PM with non-intact acrosome in swimup selected sperm population may be occurred due to the excess of ROS, which may have induced PM lipoperoxidation, compromising acrosome and PM integrity (Graham et al., 1990). It was previously demonstrated that the bulldependent effect of glutathione during IVF was related to differences in the amounts of ROS production by spermatozoa of particular bulls (Kim et al., 1999). These data may explain the bucks variation in sperm presenting intact PM and intact acrosome after swim-up technique.

It is noteworthy that $100 \mu \mathrm{M}$ of SNP promoted higher motility rate than did $50 \mu \mathrm{g} / \mathrm{mL}$ heparin exposure for goat spermatozoa. Miraglia et al. (2011) described that the enhancement of motility is induced by nitric oxide that stimulates human sperm motility via the activation of guanylate cyclase and the subsequent synthesis of cGMP. Interestingly, this concentration and time of incubation for heparin was reported as the best association for goat spermatozoa capacitation (Zhou et al., 2004). Even though their incubation conditions were similar to ours, the current findings are different, but the reasons are not clear yet. We believe that this difference may have occurred since non-intact acrosome sperm do not react with heparin, since it is not possible for heparin to fix in external acrosome membrane (Januskauskas et al., 2000).

There are innumerous studies evaluating the use of SNP in other species (Rodriguez et al., 2005; Boccia et al., 2007) than goats, mostly reporting controversial results. No significant effect of SNP on sperm capacitation was found in this study. Motility rate was similar in any concentration tested in comparison with control group. Apparently, the sperm motility observed after the use of nitric oxide has a dose-dependent effect. Therefore, this result could have been due to an insufficient dose or to the absence of any capacitating effect in goats. However, vigor was improved when any concentration of SNP (4.5-4.7) was used in relation to control group (4.2) and also in $100 \mu \mathrm{M}$ SNP group in comparison with heparin treatment. This increase in vigor is related with hyperactivated sperm, which is a type of vigorous non-linear motion that mammalian spermatozoa exhibit when they progress through the female oviduct
(Suarez and Dai, 1992). Yeoman et al. (1998) demonstrated in hamsters that nitric oxide appears to be important for the maintenance of hyperactivated motility, because when synthesis was inhibited after the start of hyperactivation, the motility proceeded to decrease.

Considering that in this study the intact PM with nonintact acrosome sperm population was similar to the control group and post-thawing analysis, we hypothesize that SNP concentrations were low enough to not cause damage to sperm PM and lower than the minimal ideal required to induce capacitation. The interpretation of the results for goat species should be carefully evaluated, since different species present particularities and physiological characteristics in relation to sensibility to different concentrations of nitric oxide.

\section{Conclusions}

This study showed for the first time that miniPercoll density gradient may be successfully used for goat frozen-thawed sperm selection. Moreover, washing by centrifugation was similar to mini-Percoll and, although non-motile sperm are possibly retained, it could be applied in goats due its ease of use and no adversely effect. The incubation with $100 \mu \mathrm{M}$ SNP resulted in better motility and vigor than heparin treatment, suggesting a dose-effect relationship.

\section{Conflict of interest}

None declared.

\section{Acknowledgments}

This research was supported by Fluminense Federal University/Proppi/Fopesq, Faperj (Grant E26/102.963/ 2012 and E26/111.694/2013) and, Embrapa (Grant 03.09. 06.021.00.00). JFF, LSCC, and FZB are CNPq fellows. CCSO and JMGSF were supported by CAPES.

\section{References}

Amann, R.P., Pickett, B.W., 1987. Principles of cryopreservation and a review of cryopreservation of stallion spermatozoa. J. Equine Vet. Sci. 7, 145-173.

Amoah, E.A., Gelaye, S., 1997. Biotechnological advances in goat reproduction. J. Anim. Sci. 75, 578-585.

Avery, B., Greve, T., 1995. Impact of Percoll on bovine spermatozoa used for in vitro insemination. Theriogenology 44, 871-878.

Boccia, L., Attanasio, L., De Rosa, A., Pellerano, G., Di Palo, R., Gasparrini, B., 2007. Effect of sodium nitroprusside on buffalo sperm capacitation in vitro. Reprod. Fertil. Dev. 19, 276-277.

Colégio Brasileiro de Reprodução Animal - CBRA, 1998. Manual para exame andrológico e avaliação de sêmen animal, 2nd ed, Belo Horizonte.

Didion, B.A., Dobrinsky, J.R., Giles, J.R., Graves, C.N., 1989. Staining procedure to detect viability and the true acrosome reaction in spermatozoa of various species. Gamete Res. 22, 51-57

Dode, M.A.N., Rodovalho, N.C., Ueno, V.G., Fernandes, C.E., 2002. The effect of sperm preparation and co-incubation time on in vitro fertilization of bos indicus oocytes. Anim. Reprod. Sci. 69, 15-23.

Graham, J.K., Kunze, E., Hammerstedt, R.H., 1990. Analysis of sperm cell viability, acrossomal integrity, and mitochonrial function using flow cytomitry. Biol. Reprod. 43, 55-64.

Hansen, P.J., 2006. Realizing the promise of IVF in cattle - an overview. Theriogenology 65, 119-125. 
Henkel, R.R., Schill, W.B., 2003. Sperm preparation for ART. Reprod. Biol. Endocrinol. 14, 108.

Januskauskas, A., Gil, J., Soderquist, L., Rodriguez-Martínez, H., 2000. Relationship between sperm responde to glycosaminoglycans in vitro and non returns rates of Swedish dairy AI bulls. Reprod. Domest. Anim. 35, 207-212.

Kim, L.H., Van Langendonckt, A., Van Soom, A., Vanroose, G., Casi, A.L., Hedriksen, P.J.M., Bevers, M.M., 1999. Effect of exogenous glutathione on the in vitro fertilization of bovine oocytes. Theriogenology 52, 537-547.

Kunathikom, S., Ko-Anantakul, S., Techatraisak, K., Treetampinich, C., Phophong, P., Karavagul, C., 1998. Comparison of two-layer Percoll gradient and mini-Percoll methods for sperm preparation. J. Med. Assoc. Thai. 81, 682-687.

Lopes, S., Jurisicova, A., Sun, J.G., Casper, R.F., 1998. Reactive oxygen species: potential cause for DNA fragmentation in human spermatozoa. Hum. Reprod. 13, 896-900.

Lv, L., Yue, W., Liu, W., Ren, Y., Li, F., Lee, K.B., Smith, G.W., 2009. Effects of sperm pretreatments and in vitro culture systems on development of in vitro fertilized embryos derived from prepubertal boer goat oocytes in China. Asian Aust. J. Anim. Sci. 22, 969-976.

Machado, G.M., Carvalho, J.O., Siqueira Filho, E., Caixeta, E.S., Franco, M.M., Rumpf, R., Dode, M.A.N., 2009. Effect of Percoll volume, duration and force of centrifugation, on in vitro production and sex ratio of bovine embryos. Theriogenology 71, 1289-1297.

Martí, E., Pérez-Pé, R., Muiño-Blanco, T., Cebrián-Pérez, J.A., 2006. Comparative study of four different sperm washing methods using apoptotic markers in ram spermatozoa. J. Androl. 27, 746-753.

Masudul Hoque, S.A., Yahia Khandoker, M.A.M., Kabiraj, S.K., Asad, L.Y., Fakruzzaman, M., Tareq, K.M.A., 2012. Effect of goat follicular fluido $\mathrm{n}$ in vitro production of embryos in Black Bengal goats. Iran. J. Appl. Anim. Sci. 2, 287-294.

Mehta, A., Sigman, M., 2014. Identification and preparation of sperm for ART. Urol. Clin. N. Am. 41, 169-180.

Miraglia, E., De Angelis, F., Gazzano, E., Hassanpour, H., Bertagna, A., Aldieri, E., Revelli, A., Ghigo, D., 2011. Nitric oxide stimulates human sperm motility via activation of the cyclic GMP/protein kinase $G$ signaling pathway. Reproduction 141, 47-54
Ord, T., Patrizio, P., Marello, E., Balmaceda, J.P., Asch, R.H., 1990. MiniPercoll: a new method of semen preparation for IVF in severe male factor infertility. Hum. Reprod. 5, 987-989.

Palomo, M.J., Izquierdo, D., Mogas, T., Paramio, M.T., 1999. Effect of semen preparation on FIV of prepubertal goat oocytes. Theriogenology 51, 927-940.

Parrish, J.J., Foote, R.H., 1987. Quantification of bovine sperm separation by swim-up method - relationship to sperm motility, integrity of acrosomes, sperm migration in polyacrylamide gel and fertility. J. Androl. 8, 259-266.

Parrish, J.J., Susko-Parrish, J.L., Winer, M.A., First, N.L., 1988. Capacitation of bovine sperm by heparin. Biol. Reprod. 38, 1171-1180.

Pereira, R.J.T.A., Run, R.K., Tuli, R.K., Wallenhorst, S., Holtz, W., 2000. The effect of heparin, caffeine and calcium ionophore A 23187 on in vitro induction of the acrosome reaction in frozen-thawed bovine and caprine spermatozoa. Theriogenology 54, 185-192.

Rho, G.J., Hahnel, A.C., Betteridge, K.J., 2001. Comparisons of oocyte maturation times and of three methods of sperm preparation for their effects on the production of goat embryos in vitro. Theriogenology 56, 503-516.

Rodriguez, P.C., O'flaherty, C.M., Beconi, M.T., Beorlegui, N.B., 2005. Nitric oxide-induced capacitation of cryopreserved bull spermatozoa and assessment of participating regulatory pathways. Anim. Reprod. Sci. 85, 231-242.

Souza-Fabjan, J.M.G., Panneau, B., Duffard, N., Locatelli, Y., Figueiredo, J.R., Freitas, V.J.F., Mermillod, P., 2014. In vitro production of small ruminant embryos: late improvements and further research. Theriogenology 81, 1149-1162.

Suarez, S.S., Dai, X., 1992. Hyperactivation enhances mouse sperm capacity for penetrating viscoelastic media. Biol. Reprod. 46, 686-769.

World Organization Health, 1999. WHO Laboratory Manual for the Examination of Human Semen and Sperm-Cervical Mucus Interaction, 4th ed. Cambridge University Press, Cambridge, UK.

Yeoman, R.R., Jones, W.D., Rizk, B.M., 1998. Evidence for nitric oxide regulation of hamster sperm hyperactivation. J. Androl. 19, 58-64.

Zhou, J.B., Wu, Y.G., Liu, L.Q., Luo, M.J., Chang, Z.L., Tan, X.W., Liu, N., Tan, J.H., 2004. Studies on in vitro capacitation of goat spermatozoa by heparin treatment. Sheng Wu Gong Cheng Xue Bao 20, 252-256 (abstract). 